\title{
Penetrating trans-abdominal bamboo stick injury: An unusual case report
}

\author{
Lalit Kumar Bansal ${ }^{\circledR}$, Raja Bhanukiran, Poras Chaudhary, Arun Kumar Gupta* \\ Department of Surgery, ABVIMS and Dr. Ram Manohar Lohia Hospital and Post Graduate Institute of Medical Education and \\ Research, New Delhi, India
}

\author{
Received: 13 October 2020 \\ Accepted: 10 January 2021 \\ Published online: 30 January 2021 \\ *Corresponding author: Arun \\ Kumar Gupta, \\ Professor, Department of Surgery, \\ ABVIMS and Dr. Ram Manohar Lohia \\ Hospital and Post Graduate Institute \\ of Medical Education and Research, \\ New Delhi, India \\ Address - H 18 Green Park Main \\ New Delhi 110016 \\ Tel: 8130368883 \\ Email: Iklbbansal@gmail.com \\ Competing interests: None. \\ Funding information: None
}

\begin{abstract}
Objective: Penetrating abdominal trauma secondary to bamboo stick injury is a rare entity in the developed world. Most of such kind of trans abdominal penetrating bamboo stick injury is associated with multiple solid and hollow viscus injuries. In developing countries like India, where nearly $70 \%$ of the population reside in rural areas, it is not that uncommon. Aim of this report is to recognition of risk factors and explain optimum surgical management in trans-abdominal bamboo stick injury.

Case Presentation: Here we describe a case of penetrating trans abdominal bamboo stick injury resulting due to fall

over a branch of bamboo stick with multiorgan damage, which was successfully managed by early surgical exploration in our institute.

Conclusion: There are many factors

which can prognosticate the penetrating trauma cases. The most important factors include a long interval between injury and surgical exploration, presence or absence of shock, and other associated organ injuries at the time of admission. Early recognition of the severity of injury with surgical management is utmost necessary. These patients have high morbidity and mortality rates due to multiorgan damage and post-operative infection.

Keywords: Penetrating trauma, Bamboo stick injury, Transabdominal injury, Exploratory laparotomy

Citation: Bansal LK, Bhanukiran R, Chaudhary P, Gupta AK. Penetrating trans-abdominal bamboo stick injury: An unusual case report. Journal of Emergency Practice and Trauma 2021; 7(2): 137-139. doi: 10.34172/ jept.2021.04.
\end{abstract}

\section{Introduction}

New Delhi, surrounded by various national highways, is a continuously growing and urbanizing state. In this regard, road traffic accidents and violence are on a rise. The age group usually affected by abdominal trauma is the young productive age group. There needs to be a local study that can identify various factors associated with abdominal trauma to improve the outcome of treatment. Patients with penetrating abdominal trauma have very high chances of hollow viscus perforation. Due to associated solid organ injury, the patient may be hemodynamically unstable, which is a higher priority in the management of the patient with blunt abdominal trauma (1). Delay in the diagnosis and treatment of the hollow viscus injury results in peritonitis, hemodynamic instability and increased mortality and morbidity. Therefore, early diagnosis and treatment are mandatory (1).

\section{Case Presentation}

A 29-year-old man was rushed into our surgical emergency with a history of fall from a tree on a vertically placed bamboo stick one hour before the admission. The patient was lying in the supine position with a thick wooden bamboo stick which had pierced through his left flank region and came out of the right hypochondrial area just below the right rib cage (Figure 1). He was unable to move due to the thick bamboo stick and was lying flat in supine posture on the stretcher. His primary survey and examination were done by the emergency critical care team. His clothes were cut carefully to completely expose him to avoid missing any other chest or abdominal injuries. The patient had history of fall from a 12 feet height of a branch of a tree while picking mangoes from the tree. A thick wooden branch entered and transfixed to his abdomen with one end entered through the left side of the abdomen and exiting on the right side of the abdomen when he fell onto the ground. He was not able to move his body, and he was carefully brought into the ambulance in a recumbent posture to avoid further injury to other organs and to prevent pain.

On examination, the patient was conscious and oriented to time, place, and person. His pulse rate was 100 per 


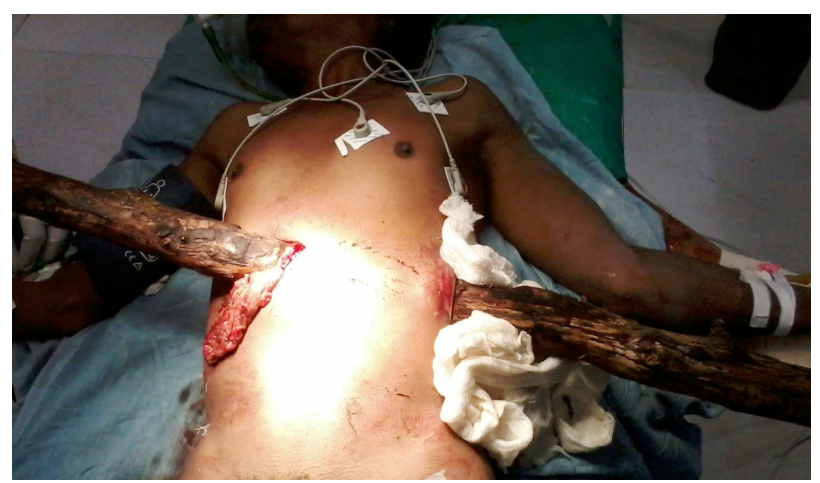

Figure 1. Photograph on admission showing bamboo stick injury of the abdomen.

minute, and blood pressure was $100 / 60 \mathrm{~mm} \mathrm{Hg}$ at the time of presentation. On abdomen examination, a thick wooden bamboo stick branch was transfixed with one end entering through $2 \mathrm{~cm}$ above the anterior superior iliac spine on the left side of abdomen and exiting $2 \mathrm{~cm}$ below to the right costal margin in midclavicular line. Part of omentum was also seen coming out from the exiting point on the right side. Tenderness was present on per abdomen examination, and bowel sounds were absent. Per rectal examination was normal. He was managed according to standard trauma guidelines. Two wide bore intravenous lines were established, and urinary catheterization was done to measure urine output. Baseline investigations were done with blood for grouping and cross-matching. Routine tetanus prophylaxis with antibiotics and pain killers were given to the patient. We did not perform any imaging investigation as the intraperitoneal breach was very obvious, and also the condition of the patient did not allow it. He was immediately shifted to the operating room for exploratory laparotomy.

Abdomen was opened transversely parallel to the direction of the bamboo stick. After opening of all layers, intraoperative findings were noted. The wooden stick was found to pierce the mid part of the sigmoid colon and the proximal part of the ileum with minimal intraperitoneal faecal contamination. Also, there were multiple mesenteric tears with a liver laceration in the right lobe. There were moderate hemoperitoneum and minimal biliary collection. Wooden stick was removed carefully to avoid further damage to intra-abdominal organs. Thorough abdominal lavage was done. The damaged part of the sigmoid colon was resected, and primary anastomosis was done. The injured proximal part of the ileum, which was found 3 feet proximal to the ileocecal junction, was resected and both ends were brought outside as double barrel ileostomy. The liver laceration was left as such because there was no active intraabdominal bleeding. After careful inspection of all other areas, the abdomen was closed in layers, and the skin was left open for healing with secondary intention.

Postoperatively the patient was shifted to the surgical
ICU for better post-operative care. Ileostomy became functioning on the second post-operative day. The only complication was post-operative sepsis suggested by continuous fever and minimal purulent drainage into the pelvic drain. Antibiotics were upgraded on the basis of routine blood and pus culture reports. Slowly the patient responded to it and was discharged on the $13^{\text {th }}$ postoperative day.

\section{Discussion}

Penetrating abdominal trauma with the bamboo stick is rare in developed countries but in countries like India where nearly $70 \%$ of the population reside in rural areas, it is not that uncommon. Young productive age group is more affected by this type of injury (1). There are many factors which can prognosticate penetrating trauma cases. The most important factors include: interval between injury and surgical exploration, presence or absence of shock, and other associated organ injuries at the time of admission (2). Penetrating abdominal Injuries are known to have high morbidity and mortality rates. Also, these injuries pose a challenge to hospitals, surgeons and critical care team for preoperative and post-operative management (3). Most of the mortality can occur within the first 24 hours (4). Clinical features of these patients depend on the injured parts of the body, organ and the shape as well as the size of the penetrating object (5). There is a high chance of intraperitoneal breach with hollow viscus perforation and other intra-abdominal visceral injuries (6). It is very important to properly expose the patient from top to bottom by completely removing clothes. Also, as bamboo stick may be a potential source of infection, prophylactic tetanus administration and broad spectrum antibiotic coverage are essential to prevent preoperative and postoperative sepsis (7). It is important to remove the foreign object as a single piece to avoid further injury and also to prevent any missing particle of foreign objects. (8). Once the wound is debrided after the foreign object is removed, a thorough lavage is mandatory. It minimizes contamination, and post-operative infection rate and the resulting wound could be left to either primary or delayed intention healing (6).

\section{Conclusion}

Transabdominal penetrating injuries with foreign bodies such as wooden or bamboo stick of tree pose a great challenge to the surgeons and critical care team. Time to reach the hospital, proper surgical management and preventing post-operative infection are the key factors for the management of the patient.

\section{Ethical issues}

Informed consent was obtained from the patient after full explanation of the purpose and nature of all procedures used. Additionally, approval was not required in our study as the patient was not under any harm during all 
procedures.

\section{Authors' contributions}

$\mathrm{LKB}$, drafting, data collection, analysis; $\mathrm{AKG}$, design, interpretation, critical analysis; Bh, data collection; PC, design, correction, final proof. Final manuscript approved by all authors.

\section{References}

1. TraumaRegister DGU, 20 years of trauma documentation in Germany--actual trends and developments. Injury 2014; 45 Suppl 3: S14-9. doi: 10.1016/j.injury.2014.08.012.

2. Gill RC, Saleem O, Mannan F, Begum S, Zafar H. Penetrating trauma to abdomen with Transfixed Wooden Branch without Intra-Peritoneal Breach: a close call. SAJ Case Rep 2018; 5(3): 304.

3. Mohan R, Ram DU, Baba YS, Shetty A, Bhandary S. Transabdominal impalement: absence of visceral or vascular injury a rare possibility. J Emerg Med 2011; 41(5): 495-8. doi: 10.1016/j.jemermed.2008.03.033.
4. Demetriades D, Murray J, Charalambides K, Alo K, Velmahos G, Rhee P, et al. Trauma fatalities: time and location of hospital deaths. J Am Coll Surg 2004; 198(1): 20-6. doi: 10.1016/j.jamcollsurg.2003.09.003.

5. Swaid F, Peleg K, Alfici R, Matter I, Olsha O, Ashkenazi I, et al. Concomitant hollow viscus injuries in patients with blunt hepatic and splenic injuries: an analysis of a National Trauma Registry database. Injury 2014; 45(9): 1409-12. doi: 10.1016/j.injury.2014.02.027.

6. Cigdem MK, Onen A, Siga M, Otcu S. Selective nonoperative management of penetrating abdominal injuries in children. J Trauma 2009; 67(6): 1284-6. doi: 10.1097/TA.0b013e3181bbd932.

7. Thomson BN, Knight SR. Bilateral thoracoabdominal impalement: avoiding pitfalls in the management of impalement injuries. J Trauma 2000; 49(6): 1135-7. doi: 10.1097/00005373-200012000-00029.

8. Horowitz MD, Dove DB, Eismont FJ, Green BA. Impalement injuries. J Trauma 1985; 25(9): 914-6. doi: 10.1097/00005373-198509000-00017. 